\title{
Encubrimiento y disrupción: ficciones y revelación de realidades sociales
}

\author{
Concealment and disruption: fictions and revelation \\ of social realities
}

RUBÉN LASHERAS RUIZ

\begin{abstract}
Resumen: El aparentemente inalterable discurrir ordinario del mundo de la vida aloja repentinas irrupciones lingüísticas capaces de interrumpir la cadena de acontecimientos que nos atan a la vida. Estas disrupciones, donde encontramos refranes, poemas, dichos, cuentos y, en general, ficciones, al catapultar representaciones posibles de los ámbitos de convivencia, al realizar representaciones de objetos y situaciones que no tienen correlato empírico, producen una fuerte sacudida en las «sedimentaciones subjetivas del saber». Las ficciones, al suspender momentáneamente el cúmulo de representaciones cotidianas, al convertir en «extraño» ese mundo establecido «hasta nuevo aviso» repleto de expectativas y convenciones, desplazan lo incognoscible hacia lo potencialmente conocible y lo evidente hacia el espacio de lo cuestionable. En definitiva, permiten arrojarse a la tarea de explorar, remover y renegociar los significados presentes en los escenarios de convivencia ordinarios.
\end{abstract}

Palabras clave: Disrupción, revelación, ficciones, realidad, cambio

\begin{abstract}
The apparently unalterable discourse hosts sudden irruptions, which, interrupts the everyday life events. These disruptions, such us proverbs, poems, stories and, in general, fictions, produce a strong jolt in the subjective knowledge to catapult the representations of the coexistence areas and to make representations of objects and situations that haven't empirical story. The fictions, to temporarily stop the daily performances and to become «strange» the established world, move the unknowable to the questionable space. In short, the language fictions can throw to explore, remove and renegotiate the meanings of the ordinary coexistence.
\end{abstract}

Key words: Disruption, revelation, fictions, reality, change.

Fecha de recepción: 27-01-2013. Fecha de aceptación: 22-02-2013.

* RUBÉN LASHERAS RUIZ (ruben.lasheras@unavarra.es) es investigador de la Cátedra UNESCO de Ciudadanía, Convivencia y Pluralismo de la Universidad Pública de Navarra, profesor asociado doctor del Departamento de Trabajo Social de la esta universidad y miembro de ALTER Grupo de Investigación. Sus líneas de investigación se enmarcan en el espacio de la diversidad religiosa, las identidades, los tránsitos migratorios, los procesos de cambio y la exclusión social. Entre sus publicaciones más recientes destacan Umbrales: minorías religiosas en Navarra (Icaria, 2012) y su participación en Crisis y fractura social en Europa. Causas y efectos en España (Colección Estudios Sociales, Obra Social «la Caixa», 2012). 


\section{Introducción: una realidad peculiar}

Existen objetos de estudio perseguidos, otros nos persiguen. Existen objetos de estudio buscados, otros los encontramos. Estos últimos son precisamente aquellos con los que tropezamos, aquellos que se encuentran sin buscar, aquellos que pasan sin llamar. Estos inesperados asistentes a la fiesta de la cotidianeidad protagonizan las siguientes páginas.

Sobre el aparentemente inalterable discurrir ordinario del mundo de la vida se suceden repentinas irrupciones capaces de interrumpir la cadena de acontecimientos que nos atan a la vida. Estas acometidas, entre las que encontramos refranes, poemas, dichos, cuentos $\mathrm{y}$, en general, ficciones, por un lado son capaces de suministrar una perspectiva novedosa de los ámbitos de sentido y, lo más importante, pueden dar pie a rupturas con ellos. En pocas palabras, son potencialmente problemáticas y problematizadoras en ese espacio conocido que nos sujeta continuamente al suelo seguro de lo que no está en cuestión y que denominamos realidad de la vida cotidiana. Como fracturas en las dinámicas ordinarias, al interrumpir la cadena de acontecimientos, no sólo permiten reparar en el propio curso de los sucesos cotidianos sino que también ofrecen ocasión para desplegar una mirada reflexiva sobre nuestra posición en el mundo-vida. Es en ellas donde, además, divisamos un importante valor heurístico, como reveladoras de los entramados más sutiles de nuestra convivencia cambiante, que derive en alguna interesante invitación a la cautela metodológica.

A esta serie de figuras lingüísticas repletas de sugestivos y valiosos esquemas para atrapar el universo cotidiano les denominaremos disrupciones, como a su modo lo hace Lotman (1999). Pero, ¿por qué se detiene nuestra atención en estos sucesos? ¿Qué nos lleva a proponerlos y a situarlos como objeto de estudio prioritario en el ámbito de las dinámicas sociales? La respuesta a estas preguntas delimita el contexto de justificación de nuestras investigaciones. Un terreno que se inicia en la comprensión del lenguaje como ámbito de construcción de sentido y que se extiende de manera especial en su condición de escenario práctico especialmente propicio para la formidable irrupción de novedades insólitas en el suelo llano, y tal vez cansino, de las rutinas y de las creencias ordinarias, aspecto sobre el que nos volcamos con especial denuedo.

Al caracterizar las disrupciones como acontecimientos aislados que destacan sobre el continuo social ponemos sobre la mesa una evidencia: en el desenvolvimiento ordinario escasean las oportunidades para iniciar la problematización de los ámbitos de sentido que nos envuelven cuando las dudas o los reparos nos asaltan. Esto es, existe un extendido acuerdo sobre una «realidad de la realidad», asumida acrítica e incuestionablemente, que impide prolongar determinadas objeciones. Si bien la sociología y, en general, el conjunto de las ciencias sociales, en el desempeño de su actividad ordinaria, tienen como «plan general» cuestionar el mundo e investigar sus estructuras, los escenarios cotidianos, aquellos donde Winkin (1984) sitúa los envites sociales más ricos en enseñanzas, fruto de su continua comparecencia, quedan a menudo al margen de indagaciones pausadas y son pasto de definiciones y análisis prefijados.

Esta común desatención hacia «los terrenos conocidos» resulta sumamente cautivadora. Como señalábamos anteriormente, con la identificación de las disrupciones desvelamos la existencia de un acuerdo en torno a lo que entendemos por realidad social y, lo más impor- 
tante, la amenaza que la emergencia de las alternativas puede suponer para su estabilidad. Por este motivo, el abordaje de las fracturas descritas requiere concentrar la atención sobre los contornos susceptibles a ellas, es decir, no es suficiente su identificación como fenómenos aislados sino que deben ser integradas en la dinámica general que permite su existencia y que le confiere su relevancia.

En suma, este pequeño trayecto tiene un doble objetivo. Por un lado, aproximarnos a las razones que hacen posible la emergencia disruptiva de estas fracturas. Por otro, demostrar que, lejos de ser «disfunciones del sistema», esta serie de rupturas proporcionan oportunidades especiales para identificar, cuestionar y cambiar realidades. Dicho de otra forma, son las ocasiones más propicias para el despliegue de nuestro formidable equipamiento para construir nuevos escenarios de convivencia y, al mismo tiempo, constituyen un escenario privilegiado para que ese plan general de exploración cuestionadora de las ciencias sociales se haga cada vez más capaz de revelar el fondo inagotable de facultad creadora al que aluden los cantos a la libertad humana.

\section{El camino hacia lo paradójico}

Como indican acertadamente Watzlawick, et al. (1981: 22), puesto que «un fenómeno permanece inexplicable en tanto el margen de observación no es lo suficientemente amplio como para incluir el ámbito donde dicho fenómeno tiene lugar», debe establecerse un acuerdo inicial básico acerca de la realidad que nos inunda, su composición y su estructura.

Uno de los tradicionales debates de la sociología y, en general, de la mayoría de las ciencias sociales, se extiende sobre la nada sencilla tarea de describir aquello que entendemos por realidad social. A la fuerte convicción de que son las nociones corrientes las que son abstrusas (Ricœur, 1995) o que la filosofía de lo concreto es ella misma enteramente abstracta (Bubner, 1984), añadimos la consabida paradoja de convertir en objeto de estudio algo de lo que, además, somos sujeto. No sólo en el sentido de estudiar una realidad de la que formamos parte, y en la que vivimos, pensamos y actuamos; sino al incluir una herramienta substancial de la realidad como es el lenguaje.

La paradoja está servida. Nuestra condición de «miembros involuntarios» nos impide seccionar la realidad, abandonar nuestro hábitat y tomar la posición de observadores exteriores. El lenguaje, pese a permitirnos llegar a nuestro objeto de estudio, es también el principal «obstáculo» (Winkin, 1984). La semiótica en tono mayor que nos descubre Lotman (1999: 159) confirma esta dificultad para «desvincularnos de ese espacio que nos envuelve del que somos parte, y al mismo tiempo es parte nuestra».

Las consecuencias de este inevitable vínculo son evidentes. Las propias miradas desplegadas constituyen tanto la realidad como todos los esfuerzos que podemos emprender para hacernos cargo de ella. Como esfera circundante, común y comunicativa que trasciende las experiencias concretas, el mundo cotidiano no traza una finca privada, sino un dominio de sentido abierto a múltiples interpretaciones.

En esta misma dirección, Marín Pedreño (1997) nos suministra otra metáfora ejemplar: «el hombre está en el mundo comiéndoselo». La dimensión interpretativa puramente humana hace que, simultáneamente al proceso de creación de realidad, las personas se abalancen sobre ella para reinterpretarla. De esta manera, el producto no llega indemne a su destino. 
Algo así como el cocinero que, encomendado a la labor de preparar platos, se dedica a dar buena cuenta de ellos. Es decir, en la vida ordinaria ingerimos $-\mathrm{y}$ tratamos de digerir - las apetitosas porciones de realidad que producimos.

Sin embargo, desde el punto de vista metodológico, estos escollos iniciales son «sólo» un nuevo escalón. Toda indagación profunda comienza por esta detección del cúmulo de dificultades que parecen obstruir cualquier paso hacia la claridad. El camino para hacer frente al desafío de lo paradójico pasa, como señalara Putnam (2000), por describir el modo como se llega a experimentarlo. En nuestro caso, atender aquellos momentos donde, de forma inesperada, se nos permite sujetar el mundo - $\mathrm{O}$ al menos donde nos conmueve la vivencia fantástica de que estamos pudiendo hacerlo-, supone un reto fascinante. Al descubrir las minúsculas raíces cotidianas que nos atan a la vida, al sacudir vivamente la complaciente y acrítica actitud de «ingenuos moradores», nos hacemos cargo de que no podemos detenernos para afirmar la existencia de un mundo compartido con un significado concreto, sino que está pendiente la tarea de determinar el modo en que éste se acepta, se impone o se rechaza.

\section{Lenguaje y creación de realidad}

En este viaje iniciado el lenguaje se erige un punto de referencia cardinal, una estación de obligada parada. A través de los símbolos, el lenguaje permite descubrir, transmitir y dar forma al mundo. En su condición de herramienta forzosa de conocimiento, revela, aprehende e internaliza subjetivamente la realidad. Es nuestra única puerta de acceso a ella. Así, en la medida en que establece paralelamente una serie de certezas que actúan a modo de cimientos sobre los que se erigen las dinámicas cotidianas, este proceso de objetivación nos lleva a hablar de creación de realidad.

$\mathrm{Al}$ adquirir el lenguaje se establecen las bases para un punto de vista implícito que acompañará el transcurso de las biografías individuales. Sin embargo, no somos habitualmente conscientes de toda esa serie de conformidades establecidas en forma de reglas y ritos que hacen exitosos los actos comunicativos cotidianos. Numerosos protocolos permiten un uso efectivo del lenguaje. Esta serie de conformidades, al establecerse desde los primeros años de vida, dificultan la posibilidad de captar la noción de su convencionalismo.

La fenomenología de Schütz (1962) concede algunas respuestas al asentamiento de esta especie de desatención generalizada. La permanencia de miradas acostumbradas parece ser un resultado inesperado de la ilimitada apertura al mundo que nos confiere el lenguaje. La proliferación de los múltiples significados sociales que el «abrirse al mundo» acarrea, tiende a desestabilizar el saber disponible. Por este motivo, es precisa la articulación del denominado «conocimiento de receta». Nos referimos a esas prescripciones que permiten no redefinir las situaciones ante cada nuevo fenómeno al servirse de referentes adquiridos en contextos con semejantes indicadores. El «conocimiento de receta», valiéndose de estas fórmulas simplificadoras aplicables en las interacciones diarias, resulta particularmente eficaz en el uso de medios típicos destinados a conseguir fines típicos en situaciones típicas.

Pero los efectos son más amplios. La puesta en práctica de este comportamiento cotidiano conlleva, además, el establecimiento de la denominada «conducta sensata» donde las acciones realizadas, además de ser comprensibles para nosotros o los observadores, deben ajustarse a un conjunto de reglas previamente definidas. Sólo así es posible salvar «proble- 
mas típicos» utilizando «medios típicos» con el objeto de lograr «fines típicos». De esta suerte, se establece el denominado conocimiento socialmente aprobado, entendido como ese conjunto de recetas que sirven a los miembros del grupo para ubicar su situación en la realidad de la vida cotidiana de una manera típica.

El resultado de esta práctica es que, si bien contribuye a facilitar el desarrollo de los encuentros ordinarios, al disponer de respuestas estandarizadas ante situaciones estandarizadas, convertimos en rutinas los fenómenos de la vida cotidiana. Al instaurarse un conjunto de tipologías y modelos biográficos predefinidos, los actores sociales sienten necesidad de adscribirse a ellos para reconciliarse con las constantes exigencias de la realidad. Ello produce un nítido desplazamiento entre creador y producto. Y seguramente sea en la fábrica de los signos donde se dé primordialmente esa estafa formidable.

\section{El proceso de reificación: de «productor» a «producto»}

Retomemos brevemente alguna de las ideas vertidas. La desigual relación existente entre la inmensa capacidad para generar información y las limitaciones para procesarla, es una de las principales causas para el establecimiento de estas prácticas rutinarias. Si bien estas prácticas tratan de ser herramientas útiles que faciliten el enfrentamiento cotidiano con un mundo ilimitado, lo que en un principio supone un sostén efectivo, se convierte paulatinamente en la única sujeción y apoyo para el desenvolvimiento ordinario. Este hecho no sólo limita la aparición del componente imprevisible ligado a la imaginación y la creatividad, sino que también limita las posibilidades de que el propio mundo se convierta en objeto de reflexión. Es entonces cuando se pone sobre la mesa la famosa paradoja que señalan Berger y Luckmann (1995: 118): «el ser humano es capaz de producir una realidad que lo niega».

Por lo tanto, si la naturaleza humana podría caracterizarse por su infinita capacidad para intervenir, modificar, transformar, cambiar y alterar una realidad que es fruto de su creación, ésta viene a expresarse con el disfraz tramposo de un ente abstracto ajeno a la voluntad de sus forjadores. La permanencia de múltiples cursos de acción socialmente compartidos y aceptados aletarga progresivamente el ejercicio de la creatividad. Los actores sociales aprehenden, así, una y otra vez, el mundo de manera reificada y se inclinan a reproducirlo como un orden preestablecido y acotado ahondando en ese paulatino distanciamiento entre productor y producto que Berger y Luckmann (1995) describen magistralmente.

Esta dinámica reificadora provocará que el mundo de la vida cotidiana se configure como «un estado de cosas aproblemático hasta nuevo aviso» donde se excluya cualquier motivo de peso y en cuya fragua reproductiva, la de los pobres Sísifos, se agoste cualquier brote que pueda irrumpir cuestionando su sentido válido.

Pero a pesar de su pesantez inmensa, todo ese cúmulo de presuposiciones instauradas y recreadas no tiene una estructura completamente cerrada, ordenada e inequívoca. En ciertas ocasiones, como queremos demostrar, este devenir normalizado es súbitamente interrumpido. El conjunto de evidencias que erigen el mundo de la vida son susceptibles de ser cuestionadas al sostenerse sobre un fondo de indeterminación. Pero si aceptamos que periódicamente surgen estos recelos, ¿cuál es el proceder del actor social ante este inicial desconcierto? 


\section{Batirse en duelo con la realidad}

Desafiar a la realidad no es una tarea sencilla. Su enorme capacidad para defenderse está fundamentada en una rotunda e innegable evidencia: pese a las posibles dudas que podamos albergar acerca de su esencia, estamos obligados a suspenderlas puesto que existimos rutinariamente en ella (Schütz, 1962). De este modo, la vida cotidiana exige intrínsecamente la suspensión de las dudas acerca del mundo creando una peculiar dinámica de ocultamiento sustentada bajo un interés fundamentalmente práctico.

El proceso es el siguiente. El acervo de conocimiento disponible suministra continuas soluciones a los problemas que presentan tanto experiencias como actos, convirtiendo estas soluciones en «explicitaciones del horizonte». Si bien estas explicitaciones no deberían finalizar, ocurre que sólo se extienden hasta el punto donde se encuentran con el pragmatismo reinante en la vida cotidiana. De ahí que inicialmente calificáramos nuestra actitud natural como «ingenua».

Toda nueva experiencia que pueda ser incorporada de forma no traumática a ese acervo de experiencias anteriores confirmará la validez del mismo. Como si de un proceso digestivo se tratara, nuevas experiencias situadas en una cola de «digestión» esperan el momento de ser absorbidas para alimentar el sistema. De esta manera, esa actitud natural mencionada, ante el rutinario flujo de experiencias que rebosa la vida cotidiana, las convierte en algo presupuesto de forma no problemática.

Si esta es la actitud que domina el devenir cotidiano, precisamos una especial motivación para ser inducidos a dar comienzo a una reflexión que llegue a propiciar un cuestionamiento de las estructuras de sentido que nos envuelven. Esto es, se requieren importantes dosis de arrojo no sólo para «abandonar» la realidad de la vida cotidiana sino especialmente para poder acometer una reflexión sobre su existencia y ensanchar así ese horizonte de indeterminación sobre el que se asientan las decisiones ordinarias (Berger y Luckmann, 1995).

En resumen, desafiar las constantes imposiciones del mundo de la vida cotidiana precisa un esfuerzo deliberado y nada fácil (Berger y Luckmann, 1995: 41). Sin embargo, esto no impide que, en ocasiones, el continuo rutinario de experiencias no problemáticas se interrumpa. Cuando ante determinadas situaciones el acervo de conocimiento no es capaz de suministrar una solución «efectiva», o simplemente se produce un abandono consciente de las respuestas pragmáticas, acontece un poderoso desafío ante aquel mundo presupuesto y rebosante de evidencias que describíamos con anterioridad. En ese momento, lo incuestionado deja de serlo y, a partir de entonces, como apunta Schütz (1962), la realidad exige una «re-explicación» de la experiencia que interrumpe el curso de la cadena de evidencias. Este es precisamente el escenario disruptivo que exigía nuestra atención y que, a continuación, trataremos de perfilar.

\section{El potencial disruptivo}

El camino trazado hasta el momento adivina una llamativa dimensión dual del lenguaje. Éste, semejante a Jano, dios de las puertas, los comienzos y los finales, representa ese carácter bifronte susceptible de cambios y transiciones al que se encomiendan aquellos que desean variar el orden de las cosas. Sus dos caras, mirando en sentidos opuestos pero componiendo una sola efigie, encarnan las peculiaridades de esta doble expresión lingüística. 
Por un lado, en los ámbitos de convivencia ordinaria, el lenguaje trata de evitar equívocos y ambiguiedades para garantizar el orden social instituido, compartido, objetivo, neutral, concordante y armónico (Held 1987).

Por otro lado, el lenguaje también puede provocar articulaciones imprevisibles que abandonen su discurrir rutinario y hagan brotar un abismo en el mundo del sentido. En estas ocasiones, cuando el lenguaje comparece de forma singular y única, emerge como un resorte para acceder a zonas oscuras o poco iluminadas del mundo de la vida.

Rappaport (2001) destaca la capacidad del discurso para escapar de lo concreto y del presente. A través del poder que le confiere la gramática, el lenguaje está en disposición de buscar palabras paralelas a lo real, del tipo: «lo que pudiera haber sido», «lo que debería ser», «lo que podría ser», «lo que nunca será», «lo que quizá siempre sea». El discurso habilita la exploración de los reinos de lo deseable, lo moral, lo adecuado, lo posible, lo fortuito, lo imaginario, lo general, así como, lo indeseable, lo inmoral y lo imposible. Esta facultad de explorar es doblemente reseñable ya que no se reduce simplemente a descubrir qué hay allí sino a crear lo que hay allí. El lenguaje despega desde lo que se concibe, con el rumbo dirigido hacia lo que puede concebirse. Además, Rappaport (2001) añade que el lenguaje no sólo hace posible este peculiar ejercicio sino que lo requiere y lo hace inevitable. Esta idea revalida nuestra propia esencia: «la humanidad es una especie que vive y que solo puede vivir en función de significados que ella misma debe inventar» (Rappaport, 2001: 32). En términos similares, Ricœur (1980), en su brillante análisis del lenguaje metafórico, señala que el discurso puede desarrollar nuevas referencias no ostensibles, es decir, un mundo, no en su sentido cosmológico, sino en su más amplia dimensión ontológica. Recalca la capacidad de la gramática para producir frases bien formadas en un número y contenido imprevisibles, y destaca el potencial que reside en la obra de arte (poema, drama, novela, etcétera) como «producción original y existencia nueva en el reino del lenguaje» (Ricœur, 1980: 138). Así, desconocidas producciones proporcionan una evidente ampliación de la perspectiva. A través de novedosos discursos se puede tener acceso a aspectos, cualidades y valores de la realidad que el lenguaje puramente descriptivo no concede. Un acercamiento que sólo es posible «gracias al juego completo entre la enunciación metafórica y la transgresión regulada de las significaciones corrientes de nuestras palabras» (Ricœur, 1980: 33).

Retomando esa correspondencia entre la imprevisibilidad del arte y la imprevisibilidad de la vida, Lotman (1999: 41) señala también cómo el contenido del lenguaje poético «es la descripción de una explosión de sentido, de un pasaje a través de los límites de lo imprevisible». Cuando determinados fenómenos se manifiestan de forma explosiva, abren un escenario nuevo cargado de posibilidades. Este autor denomina «estado de explosión» a ese espacio engendrado donde se produce una «igualación de todas las contradicciones» (Lotman, 1999: 212). Lo que parece diferente «se presenta como la misma cosa», «lo imposible deviene posible», etcétera. Este fenómeno permite que se produzcan inesperados saltos en estructuras de organización completamente diferentes renegociando y redimensionando la realidad más allá de sus confines ${ }^{1}$. La apertura del estado de explosión

1 El mundo cotidiano se desarrolla en «ámbitos finitos de sentido» a los que otorgamos el denominado «acento de realidad». Por «ámbitos finitos de sentido» entendemos, a su vez, experiencias armónicamente compatibles y coherentes entre sí que edifican un «estilo cognoscitivo». El mundo de la vida cotidiana dispone de ese carácter finito en el ámbito del sentido como también lo poseen otros como el mundo de los sueños o el mundo de 
configura un novedoso escenario donde dar cabida a numerosos conceptos (eterno, imposible, etcétera) que son expulsados de una dinámica cotidiana subordinada a un realismo práctico. Consecuentemente, el futuro emerge como el espacio de posibles estados, puesto que el propio presente aparece como un estallido de sentido todavía no desplegado que debe ser gobernado y tripulado hacia un nuevo destino.

En resumen, cuando ante la injerencia de determinadas figuras nuestro ámbito de sentido particular es sacudido y traspasado, no sólo transferimos momentáneamente el acento de realidad hacia los nuevos escenarios desplegados, sino que, además, constatamos la existencia de una pluralidad de esferas accesibles a nuestra experiencia. Tanto «saltos», como «experiencias conmocionantes» $\mathrm{O}$ «cambios de actitud», son fenómenos que tienen en común su capacidad para abrir «escenarios enfrentados» a la dinámica ordinaria. La importancia de este giro es que los nuevos horizontes no sólo permiten extender o ampliar los límites de la realidad, sino que también disponen un terreno desde el cual ensayar nuevas miradas. El cambio de perspectivas que acontece tras la irrupción de estas figuras inesperadas contribuirá a relativizar todo aquel entramado de incuestionabilidad que representa la realidad de la vida cotidiana. Pero, ¿qué tipo de «figuras» están en disposición de producir este fenómeno disruptivo?

\section{El mundo de las ficciones}

Entre el amplio abanico de figuras capaces de provocar estas fracturas en las dinámicas ordinarias, las ficciones captaron nuestra atención por dos motivos principales. En primer lugar, por su condición de realidades originales que salvan la tradicional oposición falsorealidad. En segundo lugar, por el conflicto evidente que engendran entre el escenario presentado y la realidad de acogida.

El denominado «relato de ficción» abarca un enorme espectro que va desde el cuento popular hasta la novela, pasando por la epopeya, la tragedia, la comedia, etcétera. Para entender la diferencia con el resto de géneros podríamos acercarnos a la postura histórica del arte. Entre los múltiples anhelos de los artistas, ha destacado el de reproducir la vida, reflejarla sobre lienzo o papel, capturarla y presentarla ante nuestros ojos, fruto de una actitud guiada por la idea de lo verdadero en el sentido de correspondencia y fidelidad con la realidad. De este modo, los mitos que hablan sobre el origen del arte se han detenido de forma especial en el fenómeno de la duplicación, es decir, en el desdoblamiento de la realidad: la rima aparece como producto del eco, la pintura a modo del contorno de una sombra trazado con un carboncillo, etcétera. No obstante, conviene subrayar que estas representaciones artísticas no son las únicas. El arte no puede reducirse a un propósito preferente sobre el resto. No sería muy acertado centrarse en el ejercicio de imitación y reproducción de la realidad cuando la propia obra «sucumbe» ante el poder interpretativo de sus receptores.

\footnotetext{
la ciencia. La peculiaridad reside en que sólo a través de un «salto» podemos pasar de un ámbito a otro. Este «salto» corresponde a un cambio de un estilo de vivencia por otro. Puesto que cada estilo de vivencia posee una tensión específica de conciencia, este salto «va acompañado por una experiencia conmocionante, provocada por la alteración radical de la tensión de la conciencia». En resumen, la forma de atravesar diversos ámbitos es a través de modificaciones de la tensión de la conciencia. A. Schütz y T. Luckmann: Las estructuras del mundo de la vida, Buenos Aires, Amorrortu, 1973, p. 43.
} 
En relación con los términos que venimos manejando, la ficción sería caracterizada por su alejamiento de la pretensión de verdad. Sus creaciones no requieren coincidencia absoluta con el «mundo real». El hecho de que la ficción no precise o abandone la posibilidad de una reciprocidad absoluta, pese a lo que suele ser habitual, no implica otorgarle el calificativo de «no real». En la medida en que presta atención a alguno de los mundos desplegados, es real a su manera. Por lo tanto, puede ser concebida como una realidad peculiar. Del mismo modo, tan pronto como se retira la atención, este mundo desaparece como realidad. Esto es, su realidad se entreteje en relación con nuestra vida emocional y activa desplegada. Aquello que despierta y estimula nuestro interés es real (James, 1997).

Los universos paralelos desplegados por las ficciones, como modificaciones simultáneas puntuales del mundo cotidiano, relativizan los ámbitos de sentido ordinarios y logran colocar a la realidad entre paréntesis. Esto es, suspendida, acotada y lista para ser advertida. Sin embargo, podría afirmarse que esta habilidad para escrutar realidades no ha sido completamente aprovechada. Los grandes relatos, sumergidos en las que Joyce denominaba «epifanías de lo ordinario», han sido generalmente reducidos al ámbito de «lo no serio», del divertimento, de lo «no real» o de «lo fingido», negándoles su capacidad para hablar del mundo.

Jaspers (1996) nos dirige al error que supone rechazar las respuestas literarias, es decir, considerar lo sabido científicamente como el ser mismo y, el resto, esto es, todo lo que no es posible saber de modo científico, como no existente. Esta oposición se fundamenta principalmente en un afán obsesivo por la búsqueda de una escurridiza versión idealizada de la verdad, con la intención de predecir, manejar o vencer la naturaleza (Goodman, 1990).

Evidentemente, esta noción de verdad o corrección sólo puede ser comprendida desde aquellas perspectivas donde tiene cabida. Su utilización implica la aceptación del enfoque al que pertenecen. Austin (1990: 192) indica que palabras como «verdadero» y «falso», «sólo apuntan a una dimensión general de crítica, que admite la posibilidad de sostener que en circunstancias dadas, en relación con una auditorio determinado, para ciertos fines y con ciertas intenciones, lo que se ha dicho ha sido propio o correcto, como cosa opuesta a algo incorrecta». En términos similares se pronuncia Wittgenstein (1997: 20) al señalar que para revelar la falsedad de una proposición debe considerarse «qué es válido para decidir sobre ella». Entonces, ¿qué queremos decir exactamente cuando afirmamos que algo es verdadero?

La respuesta a esta pregunta nos remonta a los primeros enunciados que formulábamos en nuestro acercamiento a la realidad cotidiana. La obviedad de los fenómenos sólo puede ser el resultado de la aceptación de antemano de una serie de dogmas y presupuestos acerca de la existencia verdadera. Es decir, lo verdadero es, como revela James (1997: 54), «lo que es bueno en materia de creencias». Las oraciones sancionadas como verdaderas son aquellas que poseen una correspondencia o adecuación con la realidad, con las creencias inmutables que la componen. Esto significa que para saber lo que es verdadero es preciso la comprensión de las proposiciones. La instauración de nuevas creencias conlleva el establecimiento de nuevos sistemas de verificación. Así, lo mismo que el lenguaje erige sus relaciones cognitivas con el mundo, éstas también son objeto de transformación. La verdad no es una propiedad innata de las palabras. Incluso, en algunas ocasiones, que sea verdadero o falso no se podrá dilucidar y deberá considerarse, como indica Austin (1990), a modo de un «enunciado aproximativo». 
Por estos motivos apuntados, las ficciones copan nuestro interés analítico. Cargadas de un lenguaje metafórico, los mundos que despliegan muestran y expresan más de lo que dicen. Si para que un enunciado, una descripción o una representación puedan ser consideradas verdaderas o válidas, es preciso que todas ellas se ajusten al mundo común del que participan, en el caso de las ficciones, este ajuste o corrección solo puede ser posible si son comprendidas en términos metafóricos. El objetivo es sobreponerse a las dificultades que entraña admitir como verdaderos una serie de enunciados aparentemente contradictorios.

Es aquí donde nace el atractivo poder de las ficciones para el ejercicio de la observación social que apuntábamos al comienzo de esta senda. Si dejamos a un lado la pretensión de verdad y correspondencia absoluta con la realidad, es decir, si nos dejamos arrastrar por las alternativas posibles, el mundo externo y la resistencia de sus objetos dejan de subyugarnos momentáneamente. A medida que depositamos nuestra atención sobre otras realidades, el motivo pragmático que gobierna nuestra actitud natural amaina. Y, además, no se detiene ahí. En su magistral dosificación de lo conocido y lo desconocido, y hechizados por la propensión casi natural que el ser humano parece tener, como señala Bruner (1994), a dotarse de una «versión narrativizada» de su entorno; las ficciones, al catapultar representaciones posibles de los ámbitos de convivencia, son susceptibles de dar inicio a la transformación y a la reorganización metafórica de lo ordinario y lo «dado» convencionalmente. Y es especialmente en su dimensión escrita donde el lenguaje parece concentrar las condiciones necesarias para desplegar esta dimensión disruptiva.

\section{Lectura y disrupción: las ventajas de las ficciones escritas}

Si en el discurso hablado, debido a la inmediatez, es prácticamente lo mismo comprender lo que el locutor quiere decir y lo que su discurso quiere decir, en el discurso escrito, al sustraerse del horizonte vivido por su autor, tanto espacial como temporalmente, lo que el texto dice ahora importa más que lo que el autor quería decir. Esta «sustracción» convierte a la interpretación en el único remedio para la debilidad del discurso que su autor ya no puede salvar. En la soledad de la lectura, el lector no encuentra una guía preestablecida para evaluar lo acertado de sus interpretaciones, lo cual, lejos de mermar el interés, contribuye a mantener vivo el proceso.

Como indica la hermenéutica de Ricœur, que tan bien enlaza con la semiótica de Greimas, el lector, sirviéndose de las estrategias y repertorios propios que le confiere su situación biográfica particular, da vida al texto en el amplio sentido de la palabra. De esta actitud creadora y actualizadora emana el placer de la lectura. El lector no encontraría atractiva una obra terminada y completamente cerrada. Su motivación aumenta al producir el texto desde la activación de sus capacidades. La lectura traslada el ejercicio creativo al lector hasta el punto de que es razonable sostener, como indica Iser (1987), que éste «escribe» el texto. Sin caer en la arbitrariedad y la inconcreción, el texto dispone espacios para que el lector, al mismo tiempo que libera sus emociones, «componga» su obra y cree las condiciones necesarias para cortocircuitarse consigo mismo. Es lo que identificamos como el momento de «hacerse-consciente».

$\mathrm{Al}$ impregnar las diferentes perspectivas internas que aporta el relato y convertirse en un «punto de visión móvil», el lector está en disposición de mirar hacia el lugar donde él 
mismo se encuentra, a «reubicarse» en el espacio que ocupa cotidianamente. La «irrealidad» producida por el texto, contribuye a retornar al mundo de partida como una realidad observable. Esto es, de forma inesperada, las ficciones disponen la realidad cotidiana como objeto de reflexión.

Este hecho, debido a los señalados obstáculos que impiden situar en el centro de la reflexión «los escenarios más conocidos», resulta de gran trascendencia. Pero lo más destacado es que esta introspección desarrolla un carácter netamente crítico. Al suspender momentáneamente el cúmulo de representaciones cotidianas, las sucesivas incursiones en el texto supondrán alteraciones en nuestra experiencia que generalmente no suelen dirigirse a validar el fondo de conocimiento disponible. Transformando en «extraño» el mundo cotidiano, se produce un doble proceso. Por un lado, lo incognoscible se desplaza hacia lo potencialmente conocible y, por otro, lo evidente ocupa el espacio de lo cuestionable.

De esta manera, las nuevas experiencias ponen en contradicción el marco de referencia incuestionado, descubren e iluminan las incoherencias e incompatibilidades del mundo establecido «hasta nuevo aviso». El conjunto de posibilidades abiertas que dominaban la experiencia ordinaria pasan a convertirse en posibilidades problemáticas que pugnan entre sí por un reconocimiento. Entonces, la articulación de mecanismos de elección y decisión deviene imprescindible. Es el paso previo hacia el cambio. Una cita con los futuros cursos de acción. Toda vivencia de ser plenamente consciente de los subterfugios de la vida es anterior a cualquier tipo de actuación sobre ella.

En suma, y retomando algunas de las ideas expuestas, si bien el desenvolvimiento en la vida cotidiana nos empuja a concebir la existencia de un orden, no nos suministra ni su naturaleza ni nuestra posición en él. El proceso de aprendizaje y adiestramiento instaura más reglas y filtros sobre la aceptabilidad y el modo en que deben ser interpretados los fenómenos sociales de lo que generalmente suponemos. Wittgenstein (1997: 307) apuntaba hacia esta idea: muchos aspectos de la realidad ordinaria no son considerados por el sencillo motivo de que siempre están ante nuestros ojos, sólo en el caso de que devengan problemáticos nuestra atención se detendrá sobre ellos.

En parecidos términos, Iser (1987) muestra cómo los formalistas rusos veían en el arte un procedimiento encargado de dificultar la percepción. Aunque pueda parecer contradictorio, estos impedimentos se convierten en germen de revelación y claridad. Al complicar la percepción, la atención sobre el propio objeto se alarga, se prolonga en el tiempo y, con ello, todas las probabilidades de escrutinio.

En resumidas cuentas, toda esa serie de versiones de realidad que articulan las ficciones y que trasgreden los «modelos de mundo», al chocar con las expectativas y el cúmulo de convenciones sociales adquiridas, «obligan» a invertir, cambiar o desplazar los esquemas contemplativos del mundo de la vida. Este es el momento clave de la disrupción. Al retornar las normas sociales vigentes en las realidades cotidianas a un espacio exterior al de su contexto, pueden ser impugnadas desde otras condiciones de operatividad que las rechacen o señalen sus insuficiencias. El ejercicio de hacer presentes las normas del propio entorno social posibilita adquirir conciencia de dónde se está aprisionado y permite arrojarse a la fascinante tarea de detallar, explorar, remover y renegociar los significados sociales adquiridos. La ficción invita a visitar ese «ningún lugar» donde divisar la relatividad de un mundo cosificado. 


\section{Conclusiones: El escenario disruptivo}

La disrupción arroja un escenario complejo de describir. Por un lado, es difícil hacer visible lo que no lo es, lo que a primera vista no es evidente. Por otro, implica dificultades similares a las de contar un sueño o una composición musical, para lo cual, el único recurso parece ser la articulación de una lengua individual. Sin embargo, sería falto de compromiso recluir estos fenómenos al ámbito particular e ignorar sus evidentes repercusiones sociales.

¿Quién no ha experimentado en alguna ocasión sentirse atrapado por las páginas de un libro y despertar súbitamente en recónditos rincones de la realidad? Al empujarnos a realizar representaciones de objetos y situaciones que no tienen correlato empírico, las ficciones producen una fuerte sacudida en las «sedimentaciones subjetivas del saber». Su lectura ataca, remueve y actualiza este espacio de ideas acumuladas para comprobar que las cosas, siendo como son, podrían ser de otra manera. De esta manera, se produce un gran paso. Del «cómo son» al «cómo podrían ser».

Su dimensión es conmocionante y, al mismo tiempo, reveladora. Desde el abstruso contorno de las nociones corrientes, despierta incongruencias y problematiza realidades, permitiendo ese acceso a zonas o aspectos de éstas que la tiranía de un lenguaje unívoco, práctico y utilitario relega a un segundo plano. Descubre evidencias y desenmascara presuposiciones. Desorienta, llena de inseguridades, cuestiona y critica. La ficción sacude esa atractiva, deseada y cómoda visión extremadamente reconfortante de una sociedad sentada sobre el horizonte. Nos traslada ante deliberaciones que el reino de lo posible, temiendo su disolución, no concede. De este modo, cada anhelo de un mundo diferente es un órdago a la realidad. Superando las constricciones del lenguaje, amplía nuestro horizonte de existencia, diluye los límites de lo imposible y habilita vías de salida del laberinto. Caminos secretos llegan a lugares que nunca soñamos. Oasis de improvisación y libertad asoman ante un mundo presupuesto y cosificado.

Desposeídas de esa pretensión de conformidad y correspondencia, en las ficciones florecen esas otras verdades muy extraordinarias (Guimaraes, 1987) que iluminan las limitaciones humanas. Incapaces de establecer lo correcto, lo deseable, lo realizable, etcétera, y abocados a, como dijera Austin (1990), conformarnos con «enunciados aproximativos»; una sensación de angustia se apodera de nosotros ante la vaguedad y contingencia de la propia existencia. La frialdad inicial de este blanco papel que hemos tratado de vestir es especialmente significativa. La vida se convierte en ese enfrentamiento, esa «lucha contra la Nada» retratada por Gabriel Marcel que, sin embargo, nos conduce bruscamente a contemplar el mundo en su totalidad y a tomar conciencia de él (Bubner, 1984).

En general, las ideas aquí vertidas despliegan grandes dosis de seducción por la no concordancia, la no correspondencia, la falta de armonía, la ruptura de la regla, el despegue de las palabras que producen súbitamente determinados juegos del lenguaje. Por eso, resulta complicado entender la ficción como refugio ante la asfixiante realidad cuando, en ella, pueden darse conmociones, evidencias y «verdades» contundentes ${ }^{2}$. La creación y participación de un mundo diferente supone una clara ruptura del orden establecido. Donde los

2 En este sentido, Ernesto Sábato no concibe - junto a otros escritores - que la literatura pueda ser considerada un «pasatiempo» o una «evasión». Por el contrario, afirma algo con lo que estamos plenamente de acuerdo, la literatura es «una forma — quizá la más completa y profunda— de examinar la condición humana». Esta experiencia, además, no suele ser agradable. El escrutinio «de las simas del corazón humano» es un ejercicio 
escépticos pueden ver ilusiones de la realidad, nosotros vemos realidades ilusionantes. Un mundo que se sostiene y recrea a base de historias no puede renunciar a su estudio. Ellas también forman parte de esos «hilos invisibles» que, en palabras de Simmel (2002), atan y desatan espontáneamente a los actores sociales.

Esta es precisamente nuestra aportación más relevante. Sin vender grandes respuestas o reinventar sociologías, proponemos una exploración (o re exploración) de los escenarios de convivencia ordinarios a partir de los horizontes que las propias ficciones nos suministran. Es decir, utilizar la dimensión disruptiva de las ficciones como una herramienta de análisis social que facilite el acceso a esos aspectos tan cotidianos que acaban siendo invisibles a las miradas acostumbradas y que, sin embargo, constituyen, en muchas ocasiones, el punto de partida de los procesos de cambio social. En definitiva, hacer retomar a los actores sociales algunas facultades desatendidas como la de emplear las narraciones en su dimensión explicativa y proyectiva del curso de nuestras vidas.

Ya lo expuso Lewis Carroll (2003: 316-317) en boca de Tentetieso en uno de sus contundentes encuentros con Alicia

- (...) ;Ya ves te has cubierto de gloria!

—No sé que significa eso de «cubrirse de gloria» — dijo Alicia.

— ¡No me extraña! —replicó Tentetieso, sonriendo despectivamente—. ¡No lo sabrás hasta que yo te lo explique! Quiero decir que mi argumentación ha sido «contundente». —No veo qué tiene que ver la «contundencia» con la «gloria» —objetó Alicia.

—Cuando yo empleo una palabra —insistió Tentetieso en tono desdeñoso— significa lo que yo quiero que signifique..., ¡ni más ni menos!

—La cuestión está en saber —objetó Alicia— - si usted puede conseguir que las palabras signifiquen tantas cosas diferentes.

—La cuestión está en saber — declaró Tentetieso— quién manda aquí... ¡isi ellas o yo!

\section{Bibliografía}

AUSTIN, J. L.: Cómo hacer cosas con palabras, Barcelona, Paidós Studio, 1990.

BERGER, P.L. y LUCKMANN, T.: La construcción social de la realidad, Buenos Aires, Amorrortu, 1995.

BRUNER, Jerome, Realidad mental y mundos posibles. Los actos de la imaginación que dan sentido a la experiencia, Barcelona, Gedisa, 1994.

BUBNER, Rüdiger, La filosofía alemana contemporánea, Cátedra, Madrid, 1984.

CARROLL, Lewis, Alicia en el País de las Maravillas - A través del espejo, Madrid, Cátedra, 2003.

GOODMAN, N.: Maneras de hacer mundos, Madrid, Visor, 1990.

GUIMARÃES ROSA, João, Gran Sertón: Veredas, Barcelona, Seix Barral, 1982.

HELD, J.: Los niños y la literatura fantástica. Función y poder de lo imaginario, Barcelona, Paidós, 1987.

agobiante y produce grandes dosis de desasosiego. El carácter de la literatura es principalmente problemático. Ernesto Sábato, El escritor y sus fantasmas, Seix Barral, Barcelona, 1979, pp. 9, 25 y 26. 
ISER, Wolfgang, El acto de leer, Madrid, Taurus, 1987.

JAMES, W.: Lecciones de pragmatismo, Madrid, Santillana, 1997.

JASPERS, Karl, Lo trágico, el lenguaje, Málaga, Ágora, 1996.

LOTMAN, Y. M.: Cultura y explosión: lo previsible y lo imprevisible en los procesos de cambio social, Barcelona, Gedisa, 1999.

MARÍN PEDREÑO, H.: De dominio público, Ensayos de teoría social y del hombre, Pamplona, Eunsa, 1997.

PUTNAM, Hilary, Sentido, sinsentido y los sentidos, Barcelona, Paidós, 2000.

RAPPAPORT, E.A.: Ritual y religión en la formación de la humanidad, Madrid, Cambridge University Press, 2001.

RICEEUR, Paul, Tiempo y narración. Configuración del tiempo en el relato histórico, México, Siglo veintiuno, 1995.

—, Ideología y utopía, Barcelona, Gedisa, 1997.

—, La metáfora viva, Madrid, Europa, 1980.

SÁBATO, E. El escritor y sus fantasmas, Seix Barral, Barcelona, 1979.

SCHÜTZ, A.: El problema de la realidad social, Amorrortu, Buenos Aires, 1962.

SCHÜTZ A. y LUCKMANN, T.: Las estructuras del mundo de la vida, Buenos Aires, Amorrortu, 1973.

SIMMEL, Georg, Cuestiones fundamentales de sociología, Barcelona, Gedisa, 2002.

WATZLAWICK, P: BEAVIN, J. y JACKSON, D.: Teoría de la comunicación humana: interacciones, patologías y paradojas, Barcelona, Herder, 1981.

WINKIN, Y.: La nueva comunicación, Barcelona, Kairós, 1984.

WITTGENSTEIN, L.: Sobre la certeza, Barcelona, Gedisa, 1997. 